\title{
Comparative trial of the effects of continuous locomotion training provided at pharmacies: a pilot study
}

Chigusa Kikuchi ${ }^{1,2^{*}}$ (D) Kyoko Yamaguchi ${ }^{2}$, Masayo Kojima ${ }^{3}$, Haruyuki Asai ${ }^{4}$, Rika Nakao $^{5}$, Yoshifusa Otake ${ }^{6}$, Junya Nagata', Shinpei Matsunami ${ }^{8}$, Asako Horiba ${ }^{9}$ and Tadashi Suzuki, ${ }^{12}$

\begin{abstract}
Background: While the world's population is growing older, healthy life expectancy is not increasing. The Japanese Orthopedic Association proposed the concept of 'locomotive syndrome,' manifested as a decline in mobility functions, and introduced a short test battery for assessing the risk of this syndrome. The test battery includes the 'stand-up test,' 'two-step test,' and '25-question Geriatric Locomotive Function Scale' (25-question GLFS). The purpose of locomotion training is to improve and sustain standing and gait functions. However, the place where locomotion training can be provided and followed up has not been decided upon. Therefore, a study was conducted to explore the effect of locomotive syndrome improvement by continuous locomotion training provided at community pharmacies. The objective of this study was to evaluate the effect of pharmacists' instructions and follow-up on the compliance and effectiveness of locomotion training.

Methods: The inclusion criteria were 1) age $\geq 65$ years and 2) decline in mobility functions. Guidance on how to perform locomotion training was provided by a pharmacist at the pharmacy. The participants performed locomotion training at home. They were tested and instructed at the pharmacy once a month for 3 months. The main outcome measures were test battery results and the percentage of number of days participants who were able to do the training at home.
\end{abstract}

Results: Eleven participants were analysed. The minimum implementation percentage was $78 \%$. Improvements were observed in 25-question GLFS, muscle strength, and standing time on one leg. Three participants no longer showed a noticeable decline in mobility function.

Conclusion: Continuous locomotion training provided at pharmacies could contribute to locomotive syndrome prevention.

Trial registration: This study was registered with the University hospital Medical Information Network Clinical Trials Registry (UMIN-CTR; identification No. UMIN000027963. Registered 28 June 2017).

Keywords: Pharmacy, Elderly, Locomotive syndrome, Locomotion training, Community, Health support

\footnotetext{
*Correspondence: kikuchi@phar.nagoya-cu.ac.jp

'Department of Clinical Pharmacy, Graduate School of Pharmaceutical

Sciences, Nagoya City University, 3-1 Tanabe-dori, Mizuho-ku, Nagoya

467-8603, Japan

${ }^{2}$ Educational Research Centre for Clinical Pharmacy, Faculty of

Pharmaceutical Sciences, Nagoya City University, 3-1 Tanabe-dori, Mizuho-ku,

Nagoya 467-8603, Japan

Full list of author information is available at the end of the article
}

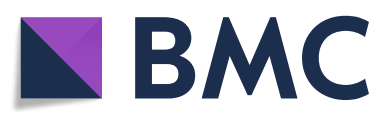

(c) The Author(s). 2020 Open Access This article is licensed under a Creative Commons Attribution 4.0 International License, which permits use, sharing, adaptation, distribution and reproduction in any medium or format, as long as you give appropriate credit to the original author(s) and the source, provide a link to the Creative Commons licence, and indicate if changes were made. The images or other third party material in this article are included in the article's Creative Commons licence, unless indicated otherwise in a credit line to the material. If material is not included in the article's Creative Commons licence and your intended use is not permitted by statutory regulation or exceeds the permitted use, you will need to obtain permission directly from the copyright holder. To view a copy of this licence, visit http://creativecommons.org/licenses/by/4.0/. The Creative Commons Public Domain Dedication waiver (http://creativecommons.org/publicdomain/zero/1.0/) applies to the data made available in this article, unless otherwise stated in a credit line to the data. 


\section{Background}

The world's elderly population is growing at an unprecedented rate. This phenomenon is considerably more pronounced in the Japanese population. Japan continues to lead the percentage of the population older than 65 years (28\%) [1]. Furthermore, the average life span of Japanese people has considerably increased in recent years. However, healthy life expectancy is shorter than overall life expectancy. The timespan from healthy life to death is approximately 10 years [2]. In Japan, the number of people who require long-term care is on the rise. In 2011, 3.783 million people needed long-term care, whereas in 2016, the number increased to 4.459 million [2]. To address this issue, it is vital to take measures that can extend the healthy life expectancy of people.

Amongst the various reasons for long-term care, the locomotor disorder is a major one, accounting for $22.7 \%$ in 2016 [2]. In 2007, the Japanese Orthopedic Association proposed the concept of 'locomotive syndrome' (Locomo), wherein a decline in mobility functions such as sit-to-stand or gait decline, was observed due to an impairment of locomotive organs [3]. To improve and sustain standing and gait functions, a method of locomotion training, called 'Locotra,' has been recommended [3]. This training consists of exercises such as standing on one leg with eyes open and squatting. The beneficial effects of these exercises have been reported by other researchers $[4,5]$. Although Locotra is safe and feasible to practice at home, the location where instructions should be provided, and subsequent follow-up has not been decided upon.

Considering the rising medical costs in Japan, it is important to prevent lifestyle-related diseases. To address this issue, the health support pharmacy system was introduced in 2016 in Japan [6-10]. The role of a pharmacy is to help the community to improve its health. However, the new services leave the contents up to each pharmacy. Pharmacies have the following three advantages: a pharmacist and a medical specialist are always present at the pharmacy, stores are present at regular intervals, and people can easily access pharmacies when compared to hospitals. We considered the possibility of establishing a new pharmacy health support by exploiting these advantages. Hence, it is the responsibility of the pharmacists to decide which service is needed and how to provide the new service.

The purpose of this study was to examine the effect of pharmacists' instructions and follow-up of Locotra in their community, as the health support pharmacy system. We evaluated pharmacist instructions and conducted a followup of Locotra in citizens of the community and tested the effects of Locotra at pharmacies.

\section{Methods}

\section{Training pharmacists}

The study was conducted at pharmacies in Aichi Prefecture and western Shizuoka Prefecture that consented to participate in this study. Before conducting the study, the pharmacists were trained to acquire sufficient knowledge and skills about Locomo and Locotra from the Care Prevention Network Association, an organization that promotes Locotra. The contents of the training were as follows: epidemiology, pathophysiology, Locomo degree judgement method, and locomotion training instruction method.

\section{Participants}

Locomo clinical decision limits were established in two stages. The beginning of the decline in mobility functions was categorized as stage 1 , and a progression in mobility function decline was categorized as stage 2 [4]. The participants of this study were those with Locomo stage 1 . Pharmacy visitors were recruited as participants for this study. A pharmacy visitor was any local resident who visited a pharmacy (with or without a prescription) to buy medicine, for consultation, or for any other reason. The inclusion criteria were as follows: (1) Japanese, aged $\geq 65$ years, and (2) inability to stand on one leg at the height of $40 \mathrm{~cm}$. The exclusion criteria were as follows: (1) inability to exercise, (2) requirement of longterm care, (3) diagnosis of mental illness, (4) exercise guidance at specialized facilities, such as gymnasiums, (5) Locomo stage 2, (6) no visit to the pharmacy after the observation period, (7) extremely limited range of joint motion, (8) pain, swelling, inflammation, damage, paralysis, and skin disorders in the lower limbs, (9) hypersensitivity to measuring instrument materials, and (10) judged by the investigator to be ineligible.

All procedures followed were in accordance with the ethical standards of author's institution Clinical Research Review Board and the Helsinki Declaration of 1964 and later versions. Informed consent was obtained from all participants before inclusion in the study. This study was registered with the University hospital Medical Information Network Clinical Trials Registry.

\section{Observation period}

The observation period was $28 \pm 7$ days from the preintervention assessment date. During the observation period, we examined the registered participants with respect to the number of visits to the pharmacy, guidance contents about health at the pharmacy, and their health status.

Clinical decision limits were established in two stages (Table 1). The following criteria were used to indicate the beginning of a decline in mobility functions and the participant was categorized as stage 1 if any of the following three conditions were met: stand-up test score $\geq$ 
Table 1 Locomotive syndrome clinical decision limits

\begin{tabular}{lll}
\hline & Stage $\mathbf{1}$ & Stage 2 \\
\hline Stand-up test score & $\geq 3$ and $<5$ & $<3$ \\
Two-step test score & $\geq 1.1$ and $<1.3$ & $<1.1$ \\
25-question GLFS & $\geq 7$ and $<16$ & $\geq 17$
\end{tabular}

Stand-up test score is expressed as the height of the lowest stool from which the subject was able to stand-up: all failed $=0,40 \mathrm{~cm}$ with both legs $=1,30 \mathrm{~cm}$ with both legs $=2,20 \mathrm{~cm}$ with both legs $=3,10 \mathrm{~cm}$ with both legs $=4,40 \mathrm{~cm}$ with a single-leg $=5,30 \mathrm{~cm}$ with a single-leg $=6,20 \mathrm{~cm}$ with a single-leg $=7$, and $10 \mathrm{~cm}$ with a single-leg $=8$. Two-step test score was calculated by normalising the maximal length of two steps taken by the participant by his/ her height; 25-question GLFS 25-question geriatric locomotive function scale

3 and $<5$, two-step test $\geq 1.1$ and $<1.3$, and 25 -question GLFS score $\geq 7$ and $<16$. The following criteria were used to indicate a progression in mobility function decline, and the subject was categorized as stage 2 if any of the three conditions were met: stand-up test score $<3$, two-step test $<1.1$, and 25-question GLFS score $\geq 16$ [3].

The leg muscle strength was evaluated using Locomoscan (Alcare Co., Ltd., Tokyo, Japan), an instrument that measures quadriceps strength $[11,12]$. Standing time on one leg with the eyes open was measured for a maximum of $60 \mathrm{~s}$, during which one leg could be raised by approximately $5 \mathrm{~cm}$ without losing balance [13]. The SF- $8^{\mathrm{Tm}}$ Health Survey (Standard, Japanese version; iHope International Co., Ltd., Kyoto, Japan) is a short, comprehensive, and versatile survey that measures health [14-16]. This survey was also employed in this study, according to the manual instruction [14]. Besides, we examined the following characteristics of the participants: age, sex, family unit, disease, participation in society, number of days spent outdoors, sleeping on a futon (Japanese style of bedding directly on the floor without a bed), or bed, and conducting household activities.

\section{Intervention method}

After the completion of the above tests, the participants were provided instructions regarding Locotra. The two exercises included in Locotra were single-leg standing with the eyes open and squatting. The former involved the participants standing on one leg with their eyes open for $1 \mathrm{~min}$. One set comprised the exercises performed once for each leg at a time. The participants were instructed to perform three sets every day [3]. For squatting, the participants slowly moved the torso down from the standing position, similar to stand-sit movement. One set comprised 5-6 slow squats and three sets had to be performed every day [3]. Thereafter, the participants visited the pharmacy once a month, where the stand-up test, two-step test, 25-question GLFS, measurement of muscle strength, SF- ${ }^{\mathrm{rm}}$ Health Survey (Standard, Japanese version), and measurement of standing time on one leg with open eyes were carried out. Moreover, we checked the implementation status of Locotra, and checked that the participant was performing Locotra following the correct procedure. The pharmacist consultation was at the discretion of the pharmacist. When the participant visited the pharmacy, the pharmacist made an appointment for the next available day. The study was completed on the third visit.

\section{Statistical analysis}

Changes in measurements due to the intervention were compared to the baseline and analysed with Wilcoxon's signed-rank test. A correlation analysis between changes in parameters and frequency of Locotra was conducted with Spearman's rank correlation coefficient. A statistical significance threshold of $5 \%$ was used $(p<0.05)$. All statistical analyses were carried out using IBM SPSS Statistics for Windows, Version 26 (IBM Corp., Armonk, NY, USA).

\section{Results}

Informed consent was obtained from 16 people, of which 12 (who met the selection criteria) were registered in the study. Twelve participants completed the study, but only 11 were included in the analysis because one participant deviated from the protocol (the first monthly inspection interval was 27 days, which was shorter than the default 28 days or more). The baseline characteristics of the participants are presented in Table 2.

The implementation rates of Locotra are presented in Table 3. The results of the single-leg standing test (with the eyes open) and squatting test were similar. At least once a day, the lowest percentage of implementation was $78 \%$ throughout the study. Similar results were observed for squats.

Table 4 presents the changes in the locomotive syndrome-related test results. After 3 months, the score of 25-question GLFS decreased significantly. In addition, leg muscle strength and standing time on one leg, with the eyes open increased. Consequently, three participants were no longer in Locomo stage 1. Furthermore, to verify the correlation between these values and the implementation rate, we performed Spearman's rank correlation coefficient. As shown in Table 5, the 25question GLFS and left leg muscle strength correlated with the implementation percentage of days for singleleg standing with the eyes open. However, no correlation was observed with the number of times nor days of locomotive training.

An increase in the number of visits to the pharmacy was reported in four out of eleven participants. At the start of the study, pharmacists provided consultation to one participant. However, by the end of the study, nine participants received consultation by the pharmacists. While consultation regarding Locomo was most frequently provided $(n=10)$, consultations regarding cold, 
Table 2 Baseline Characteristics of Participants

\begin{tabular}{|c|c|}
\hline Characteristic & Participants $(n=11)$ \\
\hline Median age, years (range) & $74(68-82)$ \\
\hline \multicolumn{2}{|l|}{ Sex } \\
\hline Male / Female & $4 / 7$ \\
\hline \multicolumn{2}{|l|}{ Family unit } \\
\hline Single / Couple / Other & $3 / 2 / 6$ \\
\hline \multicolumn{2}{|l|}{ Disease } \\
\hline $\begin{array}{l}\text { Hypertension / Diabetes / Hernia / Prostatic } \\
\text { hyperplasia / None }\end{array}$ & $5 / 2 / 1 / 1 / 2$ \\
\hline \multicolumn{2}{|l|}{ Social engagement } \\
\hline Yes / No & $9 / 2$ \\
\hline $\begin{array}{l}\text { Outdoor activity, median number of days in } \\
\text { a month (range) }\end{array}$ & $30(12-30)$ \\
\hline \multicolumn{2}{|l|}{ Sleeping on } \\
\hline Futon / Bed & $7 / 4$ \\
\hline \multicolumn{2}{|l|}{ Household activities } \\
\hline Yes / No & $11 / 0$ \\
\hline
\end{tabular}

skin, blood glucose, stress, light-headedness, health foods, and family health (each, $n=1$ ) were also provided. The purchase of over the counter drugs was reported in two participants. Information on the health status, ascertained by the pharmacist, was reported for all 11 participants, while information on body pain, medical history, and weight fluctuation was obtained from 11,5 , and 2 participants, respectively.

\section{Discussion}

In this study, we demonstrated that a pharmacy could act as a health support system and provide instructions and follow-up to the community regarding Locotra.
Several studies have documented the effectiveness of Locotra. For example, three locomotion training sessions were conducted for elderly home-dwelling people, and the results for the 25-question GLFS, stand-up test, and two-step test improved for those who attended all three sessions compared with those who were absent for more than one session [4]. In another study, it was reported that the results of the one leg standing test and sit-tostand test were improved by home-visit locomotion training, with telephone support, for elderly people who were not attending any preventive-care program [5]. However, a suitable location for the dissemination of Locotra instructions and follow-up has not been established. In this study, we successfully demonstrated that a pharmacy is a suitable place to provide instructions for Locotra and subsequent follow-up.

Adherence to Locotra is usually difficult. It has been reported that without intervention, $40 \%$ of people do not use Locotra 2 years after the administration of the training [17]. However, following-up with the participants via telephone once every 2 weeks reduced the number of people who did not perform Locotra to $14.9 \%$ [18]. In this study, the elderly participants were instructed at the pharmacies and followed up regarding Locotra once a month for 3 months. Results showed that all 11 individuals were able to continue Locotra until the end of the observation period, with a Locotra implementation percentage of at least $78 \%$. In addition, it was noted that the elderly participants could continue Locotra safely during the study. Consequently, the results of the 25-question GLFS, straight leg raising test, and standing time on one leg improved overtime. These findings were consistent with those of a previous study [4]. It should be noted that the effect of Locotra was positively correlated with

Table 3 Implementation Percentage of Locomotion Training

\begin{tabular}{|c|c|c|c|c|}
\hline & $\begin{array}{l}\text { 1st month } \\
n=11\end{array}$ & $\begin{array}{l}\text { 2nd month } \\
n=11\end{array}$ & $\begin{array}{l}\text { 3rd month } \\
n=11\end{array}$ & $\begin{array}{l}\text { Total } \\
n=11\end{array}$ \\
\hline & $\begin{array}{l}\text { Median (range) } \\
\%\end{array}$ & $\begin{array}{l}\text { Median (range) } \\
\%\end{array}$ & $\begin{array}{l}\text { Median (range) } \\
\%\end{array}$ & $\begin{array}{l}\text { Median (range) } \\
\%\end{array}$ \\
\hline \multicolumn{5}{|c|}{ Frequency of single-leg standing with the eyes open } \\
\hline None & $3(0-38)$ & $0(0-19)$ & $0(0-41)$ & $7(0-22)$ \\
\hline One time a day & $9(0-74)$ & $7(0-82)$ & $7(0-93)$ & $10(0-82)$ \\
\hline Two times a day & $24(0-84)$ & $46(0-89)$ & $54(0-82)$ & $38(0-81)$ \\
\hline Three times a day & $43(0-100)$ & $39(0-100)$ & $29(0-100)$ & $46(0-100)$ \\
\hline At least one time a day & $97(63-100)$ & $100(81-100)$ & $100(59-100)$ & $93(78-100)$ \\
\hline \multicolumn{5}{|l|}{ Frequency of squats } \\
\hline None & $3(0-38)$ & $0(0-19)$ & $0(0-41)$ & $7(0-22)$ \\
\hline One time a day & $6(0-74)$ & $5(0-82)$ & $7(0-93)$ & $10(0-82)$ \\
\hline Two times a day & $24(0-84)$ & $46(0-89)$ & $54(0-82)$ & $38(0-81)$ \\
\hline Three times a day & $43(0-100)$ & $39(0-100)$ & $29(0-100)$ & $46(0-100)$ \\
\hline At least one time a day & $97(63-100)$ & $100(81-100)$ & $100(59-100)$ & $93(78-100)$ \\
\hline
\end{tabular}


Table 4 Changes in the Locomotive Syndrome-Related Test

\begin{tabular}{|c|c|c|c|c|c|}
\hline & Baseline & 1 month & 2 months & 3 months & $\begin{array}{l}\text { Baseline vs. } \\
3 \text { months } \\
p \text {-value }\end{array}$ \\
\hline Stand-up test $(n=11)$ Median (range) & $3(3-5)$ & $3(3-5)$ & $3(3-5)$ & $4(3-5)$ & 0.083 \\
\hline Two-step test $(n=11)$ Median (range) & $1.4(1.1-1.8)$ & $1.4(1.2-1.7)$ & $1.4(1.2-1.7)$ & $1.3(1.2-1.7)$ & 0.739 \\
\hline $\begin{array}{l}\text { 25-question GLFS }(n=11) \\
\text { Median (range) }\end{array}$ & $6(1-12)$ & $3(0-12)$ & $2(0-8)$ & $1(0-7)$ & 0.014 \\
\hline No locomotive syndrome (n) & 0 & 1 & 2 & 3 & - \\
\hline \multicolumn{6}{|l|}{ Leg muscle strength $(n=8)$} \\
\hline Right leg [Newton] & 322.5 & 389 & 403 & 391 & 0.025 \\
\hline Median (range) & $(187-429)$ & $(173-471)$ & $(197-493)$ & $(239-521)$ & \\
\hline Left leg [Newton] & 361 & 363 & 424.5 & 399 & 0.025 \\
\hline Median (range) & $(238-519)$ & $(216-508)$ & $(259-559)$ & $(257-584)$ & \\
\hline \multicolumn{6}{|l|}{$\begin{array}{l}\text { Standing time on one leg with the } \\
\text { eyes open }(n=11)\end{array}$} \\
\hline Right leg [s] Median (range) & $40(12-60)$ & $58(10-60)$ & $60(7-60)$ & $47(20-60)$ & 0.044 \\
\hline Left leg [s] Median (range) & $40(3-60)$ & $60(20-60)$ & $60(20-60)$ & $60(15-60)$ & 0.021 \\
\hline \multicolumn{6}{|l|}{ SF-8 ${ }^{\text {TM }}$ Health Survey $(n=11)$} \\
\hline PCS Median (range) & $53(42-56)$ & $52(44-59)$ & $5(42-58)$ & $54(46-58)$ & 0.374 \\
\hline MCS Median (range) & $52(43-57)$ & $54(45-57)$ & $54(42-56)$ & $52(46-56)$ & 0.859 \\
\hline
\end{tabular}

25-question GLFS 25-question geriatric locomotive function scale, PCS physical component summary, MCS mental component summary

the implementation percentage of days of Locotra and not the number of Locotra exercises. Previous studies have indicated no change in the muscle function with three sets and one set of the same exercise per day [19]. It is important to educate the participants to continue practicing Locotra without trying too hard. The pharmacist can play the role of an escort runner to prevent Locomo by regularly measuring the Locomo degree and providing guidance and follow-up to Locotra for the elderly people.

The effects of other health support services have also been reported [6-10]. In the UK, Healthy Living Pharmacies has been providing these services since 2009
[20]. Furthermore, Locotra has increased the number of consultations at pharmacies. Hence, Locotra improves communication between the community and pharmacists. Our results suggest that instruction and follow-up of Locotra at pharmacies might be a novel effective service as a part of a health support pharmacy system.

Notably, this study had some limitations. The number of participants in this study was small. In addition, this study was performed without a control group. The differences in the teaching ability of pharmacists could not be analyzed. Nutrition and diet of the participants was not considered. We did not analyze the differences with respect to gender, age group, and family structure of the

Table 5 Correlations between Changes in Parameters and Frequency of Locomotion Training

\begin{tabular}{|c|c|c|c|c|c|c|}
\hline & \multicolumn{3}{|c|}{ Single-leg standing with the eyes open } & \multicolumn{3}{|l|}{ Squats } \\
\hline & Number of times & Number of days & $\begin{array}{l}\text { Implementation } \\
\text { percentage of days }\end{array}$ & $\begin{array}{l}\text { Number } \\
\text { of times }\end{array}$ & $\begin{array}{l}\text { Number } \\
\text { of days }\end{array}$ & $\begin{array}{l}\text { Implementation } \\
\text { percentage of days }\end{array}$ \\
\hline 25-question GLFS $(n=11)$ & -0.235 & -0.457 & $-0.640^{*}$ & -0.235 & -0.457 & $-0.640^{*}$ \\
\hline \multicolumn{7}{|l|}{ Leg muscle strength $(n=8)$} \\
\hline Right leg & -0.167 & -0.390 & -0.386 & -0.167 & -0.390 & -0.386 \\
\hline Left leg & -0.024 & 0.561 & $0.747^{*}$ & -0.024 & 0.561 & $0.747^{*}$ \\
\hline \multicolumn{7}{|l|}{$\begin{array}{l}\text { Standing time on one leg } \\
\text { with the eyes open }(n=11)\end{array}$} \\
\hline Right leg & -0.187 & -0.580 & -0.280 & -0.187 & -0.580 & -0.280 \\
\hline Left leg & 0.193 & 0.413 & 0.451 & 0.193 & 0.413 & 0.451 \\
\hline
\end{tabular}

Values are expressed as Spearman's rank correlation coefficient ( $\rho$-value) for nonparametric variables. ${ }^{*} p<0.05$. 25 -question GLFS 25 -question geriatric locomotive function scale 
participants. Thus, in future, it is necessary that the effects of continuous locomotion training should be investigated based on the characteristics of the participants. Furthermore, the results require validation in a larger comparative study. Nevertheless, the results from this study clearly indicated that Locotra may be applied at pharmacies, and thereby extend the healthy life expectancy of citizens.

\section{Conclusions}

Pharmacists provided locomotive training instructions to elderly people at the pharmacy. The elderly were able to continue locomotive training for 3 months. Improvements were observed in 25-question GLFS, muscle strength, and standing time on one leg. Thus, continuous locomotion training provided at the pharmacies could contribute to the prevention of locomotive syndrome.

\section{Abbreviations \\ Locomo: Locomotive syndrome; 25-question GLFS: 25-question Geriatric Locomotive Function Scale; UMIN-CTR: University hospital Medical Information Network Clinical Trials Registry}

\section{Acknowledgements}

We would like to thank all the study participants. We would also like to acknowledge the contribution by the research assistant, Ms. Akane Sekiya. We would like to thank Mr. Masanori Takahara, Mr. Akinori Miyata, and Dr. Shigeki Miyata for providing their assistance in pharmacist training. Finally, we would like to express our deep gratitude to Mr. Norimasa Umemura, Mr. Takuji Yamazaki, and Mr. Masaharu Takao for their cooperation in conducting the research at the pharmacies.

\section{Authors' contributions}

All authors contributed to the study conception and design. Material preparation, data collection, and analysis were performed by $C K, K Y, M K, H A$, $\mathrm{RN}, \mathrm{YO}, J \mathrm{~N}, \mathrm{SM}, \mathrm{AH}$, and TS. The first draft of the manuscript was written by CK, and all authors commented on different versions of the manuscript. All authors read and approved the final manuscript.

\section{Funding}

This work was supported by a Grant in Aid for Research at Nagoya City University and a grant from OTC Self-Medication Promotion Foundation. Furthermore, a part of this work was supported by JSPS KAKENHI Grant Number JP18K06754.

\section{Availability of data and materials}

The datasets used and/or analyzed during the current study are available from the corresponding author on reasonable request.

\section{Ethics approval and consent to participate}

Written informed consent was obtained from all participants. All procedures followed were in accordance with the ethical standards of the Nagoya City University Hospital Clinical Research Review Board (Nagoya City University Graduate School of Medical Science; date of approval: 23 May 2017; approval number: 46-17-0001), and with the Declaration of Helsinki (1964 and later versions). This study was registered with the University hospital Medical Information Network Clinical Trials Registry (UMIN-CTR; identification No. UMIN000027963. Registered 28 June 2017, https://upload.umin.ac.jp/cgiopen-bin/ctr/ctr_view.cgi?recptno=R000032034).

\section{Consent for publication}

Not applicable.

\section{Competing interests}

The authors declare that they have no competing interests.

\section{Author details}

'Department of Clinical Pharmacy, Graduate School of Pharmaceutical Sciences, Nagoya City University, 3-1 Tanabe-dori, Mizuho-ku, Nagoya 467-8603, Japan. ²Educational Research Centre for Clinical Pharmacy, Faculty of Pharmaceutical Sciences, Nagoya City University, 3-1 Tanabe-dori, Mizuho-ku, Nagoya 467-8603, Japan. ${ }^{3}$ Department of Medical Education, Graduate School of Medicine, Nagoya City University, 1 Kawasumi, Mizuho-ku, Nagoya 467-8603, Japan. ${ }^{4}$ Asai Pharmacy Tachibana Branch, 6-24-1 Tachibana-cho, Tsushima, Aichi 496-0038, Japan. ${ }^{5}$ Haruka Pharmacy Sakoh, 2-5-11 Sakoh, Nishi-ku, Nagoya 451-0052, Japan. ${ }^{6}$ Yamazaki Pharmacy Kamijima Branch, 2-11-10 Kamijima, Naka-ku, Hamamatsu 433-8122, Japan. ${ }^{7}$ Kyowa Pharmacy Kariya Ekimae Branch, 1-58-102 Minamisakura-cho, Kariya, Aichi 448-0841, Japan. ${ }^{8}$ Shoeido Pharmacy, 1-48-101 Yutaka, Minami-ku, Nagoya 457-0863, Japan. ${ }^{9}$ Olive Pharmacy Asada Branch, 302 Nishimaeda, Asada-cho, Nisshin, Aichi 470-0124, Japan.

Received: 17 July 2020 Accepted: 11 November 2020

Published online: 23 November 2020

\section{References}

1. United Nations. World population prospects 2019: Data booklet. 2019 https://population.un.org/wpp/Publications/Files/WPP2019_DataBooklet.pdf. Accessed 16 July 2020.

2. Cabinet Office Japan. Annual report on the ageing society [Summary] FY 2019. 2019. https://www8.cao.go.jp/kourei/english/annualreport/2019/pdf/2 019.pdf. Accessed 16 July 2020.

3. Nakamura K, Ogata T. Locomotive syndrome: definition and management Clin Rev Bone Miner Metab. 2016;14:56-67.

4. Kota M, Moriishi M, Hazama A, Hiramoto K. Assessment of the effects of a group intervention program used in home-dwelling elderly individuals to promote home exercise and prevent locomotive syndrome. J Phys Ther Sci. 2019;31:470-4.

5. Ito S, Hashimoto M, Aduma S, Yasumura S. Effectiveness of locomotion training in a home visit preventive care project: one-group pre-intervention versus post-intervention design study. J Orthop Sci. 2015;20:1078-84.

6. Um IS, Krass I, Armour C, Gill T, Chaar BB. Developing and testing evidencebased weight management in Australian pharmacies: a healthier life program. Int J Clin Pharm. 2015;37:822-33.

7. Fujita N, Nabetani N, Umemura N, Kikuchi C, Suzuki T. Lifestyle improvement through continuous measurements of hemoglobin A1c levels and lifestyle checks at the community pharmacy in three cases. Yakugaku Zasshi. 2016;136:1445-8.

8. Wada Y, Wada Y, Ennyu S, Shimokawa Kl, Ishii F. Ability of community pharmacists to promote self-care and self-medication by local residents [l]: improvements in bone mineral density. Drug Discov Ther. 2017;1 1:35-40.

9. Hirota N, Inagaki M, Matsumura N, Utsunomiya R. An outcome evaluation of the health support pharmacy efforts to improve health literacy. Jpn J Pharm Health Care Sci. 2018:44:244-50.

10. Suzuki R, Suzuki T, Kikuchi C. Improvements in lifestyle from a lifestyle consecutive self-review at a pharmacy. Yakugaku Zasshi. 2019;139:1047-54.

11. Omori G, Koga Y, Watanabe H, Tanaka M, Nawata A, Narumi K, et al. Quadriceps muscle strength and its relationship to radiographic knee osteoarthritis in Japanese elderly. J Orthop Sci. 2013;18:536-42.

12. Ohta J, Seki M, Ao M, Okajima R, Kuwabara A, Takaoka H, Aoyama K, Tanaka K. Comparison of lower leg muscle strength and grip strength for diagnosing slower gait speed in the elderly. Osteoporos Sarcopenia. 2017:3:128-31.

13. Seichi A, Hoshino Y, Doi T, Akai M, Tobimatsu Y, Kita K, Iwaya T. Determination of the optimal cutoff time to use when screening elderly people for locomotive syndrome using the one-leg standing test (with eyes open). J Orthop Sci. 2014;19:620-6.

14. Fukuhara S, Suzukamo Y. Manual of the SF-8 Japanese version. Kyoto: iHope International Corporation; 2004

15. Turner-Bowker DM, Bayliss MS, Ware JE, Kosinski M. Usefulness of the SF-8 health survey for comparing the impact of migraine and other conditions. Qual Life Res. 2003;12:1003-12.

16. Tokuda Y, Okubo T, Ohde S, Jacobs J, Takahashi O, Omata F, Yanai H, Hinohara S, Fukui T. Assessing items on the SF-8 Japanese version for health-related quality of life: a psychometric analysis based on the nominal categories model of item response theory. Value Health. 2009;12:568-73. 
17. Arai T, Fujita H, Maruya K, Asahi R, Morita Y, Ishibashi H. Follow-up questionnaire survey about exercise adherence after the "locomotion training workshop". J Jpn Osteoporosis Soc. 2018;4:171-6.

18. Arai T, Fujita H, Maruya K, Yoshizawa S, Asahi R, Morita Y, et al. The investigation of improvement effect on physical function and its sustainability after 6 month by "LOCOMO CALL" program as municipal nursing care prevention project. J Jpn Osteoporosis Soc. 2018:4:531-40.

19. Radaelli R, Brusco CM, Lopez P, Rech A, Machado CLF, Grazioli R, Müller DC, Tufano JJ, Cadore EL, Pinto RS. Muscle quality and functionality in older women improve similarly with muscle power training using one or three sets. Exp Gerontol. 2019;128:110745.

20. Brown D, Portlock J, Rutter P, Nazar Z. From community pharmacy to healthy living pharmacy: positive early experiences from Portsmouth, England. Res Social Adm Pharm. 2014;10:72-87.

\section{Publisher's Note}

Springer Nature remains neutral with regard to jurisdictional claims in published maps and institutional affiliations.

Ready to submit your research? Choose BMC and benefit from:

- fast, convenient online submission

- thorough peer review by experienced researchers in your field

- rapid publication on acceptance

- support for research data, including large and complex data types

- gold Open Access which fosters wider collaboration and increased citations

- maximum visibility for your research: over $100 \mathrm{M}$ website views per year

At $\mathrm{BMC}$, research is always in progress.

Learn more biomedcentral.com/submissions 